\title{
Bridging thoracic endovascular aneurysm repair for a late rupture following aortic coarctation angioplasty
}

\author{
Nelson F. G. Oliveira, ${ }^{1,2}$ João A. Castro, ${ }^{1}$ José D. Martins, ${ }^{3}$ Anita Quintas, ${ }^{1}$ Sérgio Laranjo, ${ }^{3}$ Hugo Valentim, ${ }^{1}$ \\ Fátima Pinto, ${ }^{1}$ Luís M. Capitão ${ }^{1}$ \\ ${ }^{1}$ Department of Angiology and Vascular Surgery, Santa Marta Hospital, Lisbon; ${ }^{2}$ Department of Angiology and Vascular \\ Surgery, Divino Espírito Santo Hospital, Ponta Delgada; ${ }^{3}$ Department of Pediatric Cardiology, Santa Marta Hospital, \\ Lisbon, Portugal
}

\begin{abstract}
Introduction: Thoracic endovascular aneurysm repair has been employed to treat late complications after aortic coarctation correction. However, its use in children has seldomly been reported. Case report: We present the case of a 15-year-old child who presented with a ruptured aneurysm of the descending aorta complicated later by an aortic-oesophageal fistula following aortic coarctation stenting that was managed with multiple bridging endovascular interventions until a definitive repair was performed. Conclusion: Thoracic endovascular aneurysm repair may be used successfully as a bridging intervention to a definitive repair in children with life-threatening aortic complications following aortic coarctation repair.
\end{abstract}

Keywords: Aortic coarctation; thoracic aneurysm rupture; thoracic endovascular aneurysm repair; aortic-oesophageal fistula

Received: 2 May 2015; Accepted: 2 August 2015; First published online: 8 September 2015

A ORTIC COARCTATION OCCURS IN UP TO FOUR in 10,000 newborns, representing $5-8 \%$ of all congenital cardiac abnormalities. ${ }^{1}$ Percutaneous methods have emerged as an alternative to open surgery for the treatment of aortic coarctation in selected patients. ${ }^{2}$ Among the possible complications following intervention is late aneurysm formation. ${ }^{3,4}$ To minimise the risk of this event as well as the risk of aortic rupture or restenosis, primary stenting is preferred over balloon angioplasty for primary aortic coarctation. $^{5,6}$ Particularly, covered stents have been favoured in patients with complex anatomy or complications following previous percutaneous intervention. $^{7,8}$

We present the case of an adolescent who presented a late thoracic aortic aneurysm rupture following aortic angioplasty who was managed initially by endovascular means.

Correspondence to: N. F. Gomes Oliveira, Hospital do Divino Espírito Santo, Avenida D. Manuel I, 9500 Ponta Delgada, São Miguel Açores, Portugal. Tel: +296203000; Fax: + 296203438; E-mail: nfgoliveira@sapo.pt

\section{Case report}

We report the case of a 15-year-old boy upon whom an aortic angioplasty with a covered stent (Advanta ${ }^{\mathrm{TM}} \mathrm{V} 12$ Atrium covered stent, $12 \times 29 \mathrm{~mm})$ had been performed 2 years earlier for an aortic coarctation with a peak-to-peak systolic gradient of $40 \mathrm{mmHg}$. His past medical story was notorious for systemic hypertension, and on the workup a bicuspid aortic valve was identified. A year after the first intervention, a significant restenosis was diagnosed (baseline peakto-peak systolic gradient of $20 \mathrm{mmHg}$ ) leading to an additional angioplasty and covered stent implantation (Advanta V12 Atrium $14 \times 29 \mathrm{~mm}$ ).

Fifteen months after the second intervention, the patient presented to the emergency department with complaints of fatigue, dyspnoea, and left thoracic pain. These symptoms had progressively worsened over the previous 3 weeks. A thoracic computerised tomography (CT) angiography was performed after detection of an enlarged mediastinum and a collapsed left lung on a chest radiograph, confirming an intact thoracic aortic aneurysm with $5.8 \mathrm{~cm}$ of maximum 


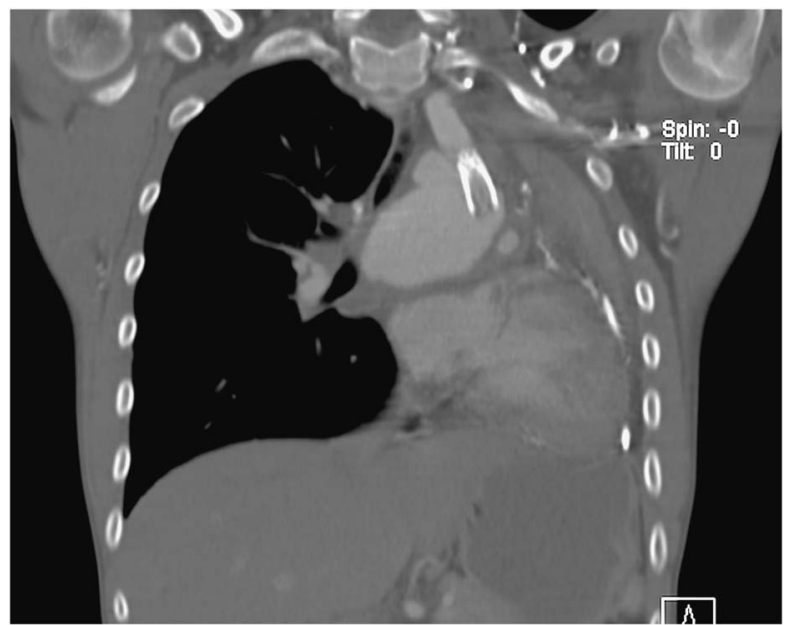

Figure 1.

$C T$ angiography reconstruction demonstrating the ruptured descending aorta aneurysm.

diameter (Fig 1). No signs of rupture were reported at this point. The patient was then transferred for consultation by his assistant paediatric cardiologist. While under observation, the patient presented a sudden stab-like thoracic pain, which radiated to the interscapular area and became hypotensive. On the laboratorial workup upon arrival, a decrease in his haemoglobin level was already present (from 11.4 to $9.0 \mathrm{~g} / \mathrm{dl}$ ) when compared with the previous workup from his local emergency department. This patient was immediately discussed among the Departments of Vascular Surgery, Cardiothoracic Surgery, and Paediatric Cardiology. A thoracic endovascular aneurysm repair was preferred as an initial bridging therapy as he had become hypotensive and a conventional aneurysm repair was deemed excessively risky. The patient was immediately transferred to the operating theatre where the thoracic aneurysm rupture was confirmed on angiography. To match device sizing to the patient's morphology, two components were required. A first $16-20 \mathrm{~mm}$ iliac extension of an abdominal aortic endograft (Endurant ${ }^{\circledR}$, Medtronic, Santa Rosa, California, United States of America) was deployed proximally, sealing in Ishimaru's zone 3, and was extended distally with a $23 \mathrm{~mm}$ iliac limb (Excluder, Gore \& Associates, Flagstaff, Arizona, United States of America). (Fig 2). The immediate postoperative period was uneventful. A postoperative CT angiography performed 1 week after the intervention confirmed the complete exclusion of the aneurysm without any endoleaks. During hospitalisation the patient remained haemodynamically stable and the left lung progressively re-expanded. The patient was discharged home after 2 weeks of hospitalisation awaiting a definitive repair.

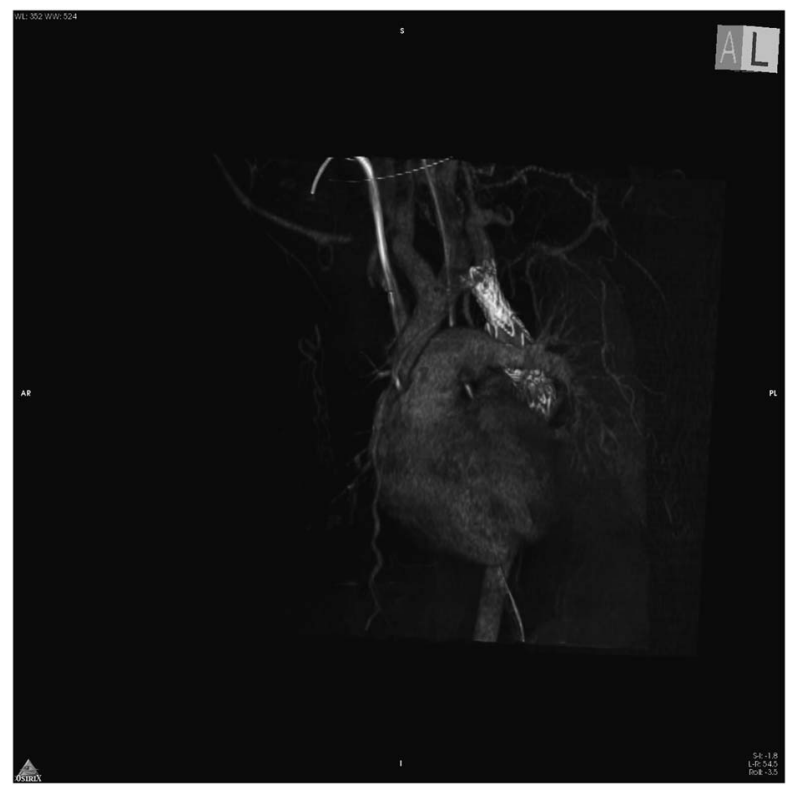

Figure 2.

Three-dimensional CT angiography reconstruction following thoracic endovascular aneurysm repair demonstrating exclusion of the aneurysm, without endoleaks.

During an outpatient visit for a scheduled transthoracic echocardiography 1 week after discharge, the patient presented an abundant haematemesis followed by syncope and shock (systolic pressure of $54 \mathrm{mmHg}$ ). An aortic-oesophageal fistula was assumed and the patient was rushed to the operating room where the fistula was confirmed as well as a type $1 \mathrm{~A}$ endoleak. A $21 \mathrm{~mm}$ thoracic stentgraft (Gore TAG) was deployed, sealing proximally, excluding the left subclavian artery. Owing to unintentional partial coverage, however, a left common carotid artery bailout stent was required (Fig 3), which was achieved from the femoral access. An intraoperative haemoglobin concentration of $5.4 \mathrm{~g} / \mathrm{dl}$ was confirmed and the patient underwent intensive transfusional support. The first postoperative $\mathrm{CT}$ angiography confirmed the successful exclusion of the aortic-oesophageal fistula, without any detectable endoleaks. The patient was kept on total parenteral nutrition and empiric antibiotherapy with meropenem and vancomycin. A few days later, a fever $\left(38.0^{\circ} \mathrm{C}\right)$ developed despite persistently negative blood cultures. On a second postoperative CT the oesophageal defect was again identified and endograft infection was assumed, although clear signs of infection were not reported. At this time, an open conversion was deemed unavoidable and the patient was transferred to a specialised cardiac surgical centre.

At this centre, the patient was initially treated with a homograft aortic interposition under circulatory arrest. The left subclavian artery was revascularised at this intervention and all 


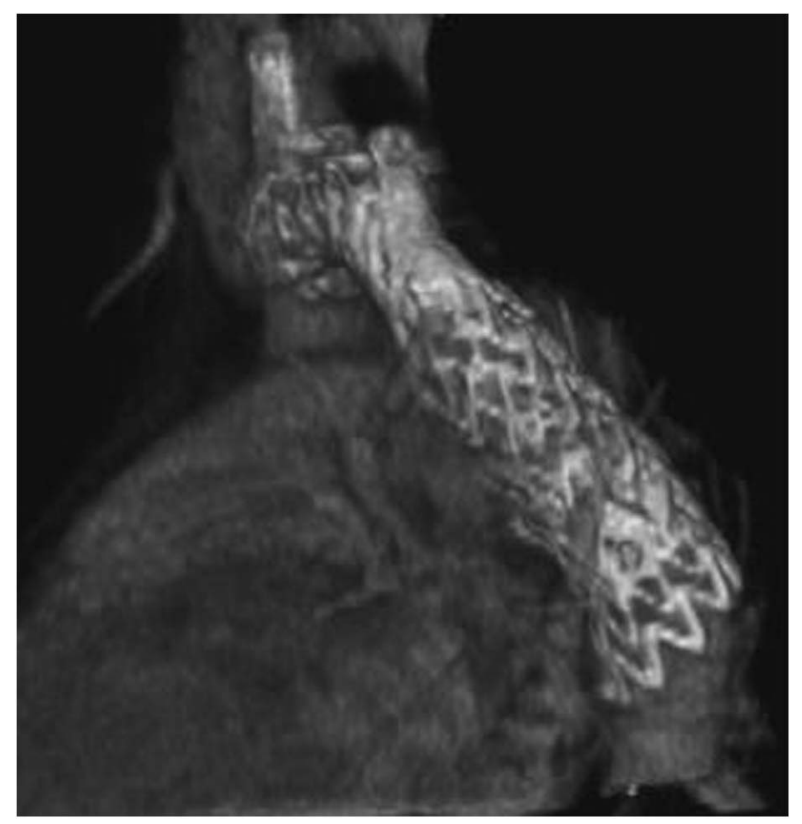

Figure 3 .

Three-dimensional CT angiography reconstruction of the postoperative control following re-do thoracic endovascular aneurysm repair, with bailout left carotid stenting.

endoluminal devices were removed. The oesophageal fistula was excluded with primary closure and a latissimus dorsi flap was tailored to wrap around the homograft, covering the fistula. However, on the 25th postoperative day, following the drainage of an infected haemothorax, the patient presented haematemesis, which was treated with endoscopic oesophageal clipping. On the 46th postoperative day, the patient presented a massive haemothorax due to homograft disruption. A thoracic endovascular aneurysm repair was once again performed with the patient severely shocked, as a bridge to a second open surgery, which would be performed 22 days later. The homograft and stentgraft were explanted; the distal thoracic aortic stump was ligated, as well as the left subclavian and common carotid arteries, and an extra-anatomic ascending aorta to a descending aorta bypass was performed. During the early postoperative period, compression of the left bronchus and pulmonary atelectasis required elective intubation, but was otherwise uneventful. An oesophagography confirmed the complete healing of the fistula, and progressively oral intake was reinstated.

After an overall period of $\sim 5$ months of hospitalisation since clinical presentation, the patient was discharged home. Antibiotherapy was continued for another month with Moxifloxacin and Linezolid. After 6 months of follow-up, no signs of relapse of the aortic-oesophageal fistula have been identified.

\section{Discussion}

Thoracic aortic aneurysm rupture is a highly fatal condition with a reported mortality rate of $97-100 \%$. Owing to its reduced perioperative morbidity and mortality when compared with open surgery, thoracic endovascular aneurysm repair has emerged as an alternative in both elective and emergent treatment of late aneurysms following aortic coarctation surgery in adults. ${ }^{10,11}$ Besides being controversial, however, thoracic endovascular aneurysm repair in children is challenging. Small access vessels, unavailability of approved endografts, and largely unknown long-term outcomes have precluded thoracic endovascular aneurysm repair in this group of patients. ${ }^{12}$ Moreover, patients with aortic coarctation may have a hypoplastic isthmus and associated severe aortic angulation at this level, thus requiring additional consideration during endovascular repair planning.

Wu et al reported the case of an acute aortic rupture immediately after aortoplasty in a 9-year-old child with Turner syndrome. In this case, an iliac limb graft (Cook, Bloomington, Indiana, United States of America) was deployed with resource to open sternotomy because of access vessel restrains at the iliac and femoral level. ${ }^{13}$ In our patient, a femoral access was possible. Device selection took into account the morphological restrains of the hypoplastic isthmic aorta. In this case, excessive oversizing was avoided to reduce the risk of endograft collapse. ${ }^{14,15}$ Although used in an off-label indication, the device initially excluded the ruptured aneurysm. Nevertheless, we hypothesise that, because of the inability of this non-dedicated device to cope with the acute angulation at the proximal landing zone and lack of active fixation, a proximal "birdbeak" developed, which ultimately lead to device migration, proximal type 1 endoleak, aneurysm repressurisation, and secondary rupture. Decision not to deploy the endograft initially proximal to the left subclavian artery was based upon the temporary intention of this repair and the risk of stroke and spinal cord ischaemia in a haemodynamically unstable patient. ${ }^{16-18}$

Our patient subsequently developed an aorticoesophageal fistula, which is a well-known and feared complication that occurs in up to $2 \%$ of patients following thoracic endovascular aneurysm repair. ${ }^{19,20}$ In this clinical scenario, thoracic endovascular aneurysm repair has also been reported to be effective in preventing immediate exsanguination. ${ }^{21}$ However, the results in the mid-term are poor, and therefore this method has been regarded only as a bridging intervention rather than a definitive treatment. ${ }^{21,22}$

In our patient, immediate exsanguination due to thoracic aortic aneurysm rupture, followed by a secondary aortic-oesophageal fistula and finally by an 
aortic homograft disruption, was prevented with thoracic endovascular aneurysm repair, thus allowing patient stabilisation and ultimately definitive correction.

\section{Conclusion}

In children with life-threatening aortic complications such as a ruptured thoracic aneurysm or an aorticoesophageal fistula, thoracic endovascular aneurysm repair may be a life-saving bridging intervention.

\section{Acknowledgements}

None.

\section{Financial Support}

This research received no specific grant from any funding agency, commercial, or not-for-profit sectors.

\section{Conflicts of Interest}

None.

\section{References}

1. Rao PS. Coarctation of the aorta. Curr Cardiol Rep 2005; 7: 425-434.

2. Luijendijk P, Bouma BJ, Groenink $M$, et al. Surgical versus percutaneous treatment of aortic coarctation: new standards in an era of transcatheter repair. Expert Rev Cardiovasc Ther 2012; 10: 1517-1531.

3. Beekman RH, Rocchini AP, Dick M 2nd, et al. Percutaneous balloon angioplasty for native coarctation of the aorta. J Am Coll Cardiol 1987; 10: 1078-1084.

4. Rao PS. Balloon angioplasty of native coarctation of the aorta. J Invasive Cardiol 2000; 12: 407-409.

5. Suarez de Lezo J, Pan M, Romero M, et al. Immediate and followup findings after stent treatment for severe coarctation of aorta. Am J Cardiol 1999; 83: 400-406.

6. Krasemann T, Bano M, Rosenthal E, Qureshi SA. Results of stent implantation for native and recurrent coarctation of the aorta-followup of up to 13 years. Catheter Cardiovasc Interv 2011; 78: 405-412.

7. Collins N, Mahadevan V, Horlick E. Aortic rupture following a covered stent for coarctation: delayed recognition. Catheter Cardiovasc Interv 2006; 68: 653-655.

8. Kothari SS. Dissection after stent dilatation for coartation of aorta. Catheter Cardiovasc Interv 2004; 62: 421, author reply.
9. Johansson G, Markstrom U, Swedenborg J. Ruptured thoracic aortic aneurysms: a study of incidence and mortality rates. J Vasc Surg 1995; 21: 985-988.

10. Botta L, Russo V, Oppido G, et al. Role of endovascular repair in the management of late pseudo-aneurysms following open surgery for aortic coarctation. Eur J Cardiothorac Surg 2009; 36: 670-674.

11. Ince $\mathrm{H}$, Petzsch $\mathrm{M}$, Rehders $\mathrm{T}$, et al. Percutaneous endovascular repair of aneurysm after previous coarctation surgery. Circulation 2003; 108: 2967-2970.

12. Karmy-Jones R, Hoffer E, Meissner M, Bloch RD. Management of traumatic rupture of the thoracic aorta in pediatric patients. Ann Thorac Surg 2003; 75: 1513-1517.

13. Wu IH, Wu MH, Chen SJ, Wang SS, Chang CI. Successful deployment of an iliac limb graft to repair acute aortic rupture after balloon aortoplasty of recoarctation in a child with Turner syndrome. Heart Vessels 2012; 27: 227-230.

14. Jonker FH, Schlosser FJ, Geirsson A, Sumpio BE, Moll FL, Muhs BE. Endograft collapse after thoracic endovascular aortic repair. J Endovasc Ther 2010; 17: 725-734.

15. Canaud L, Alric P, Desgranges P, Marzelle J, Marty-Ane C, Becquemin JP. Factors favoring stent-graft collapse after thoracic endovascular aortic repair. J Thorac Cardiovasc Surg 2010; 139: $1153-1157$.

16. Buth J, Harris PL, Hobo R, et al. Neurologic complications associated with endovascular repair of thoracic aortic pathology: incidence and risk factors. a study from the European Collaborators on Stent/Graft Techniques for Aortic Aneurysm Repair (EUROSTAR) registry. J Vasc Surg 2007; 46: 1103-1110; discussion 10-1.

17. Peterson BG, Eskandari MK, Gleason TG, Morasch MD. Utility of left subclavian artery revascularization in association with endoluminal repair of acute and chronic thoracic aortic pathology. J Vasc Surg 2006; 43: 433-439.

18. Feezor RJ, Martin TD, Hess PJ, et al. Risk factors for perioperative stroke during thoracic endovascular aortic repairs (TEVAR). J Endovasc Ther 2007; 14: 568-573.

19. Eggebrecht H, Mehta RH, Dechene A, et al. Aortoesophageal fistula after thoracic aortic stent-graft placement: a rare but catastrophic complication of a novel emerging technique. JACC Cardiovasc Interv 2009; 2: 570-576.

20. Chiesa R, Melissano G, Marone EM, Marrocco-Trischitta MM, Kahlberg A. Aorto-oesophageal and aortobronchial fistulae following thoracic endovascular aortic repair: a national survey. Eur J Vasc Endovasc Surg 2010; 39: 273-279.

21. Jonker FH, Heijmen R, Trimarchi S, Verhagen HJ, Moll FL, Muhs BE. Acute management of aortobronchial and aortoesophageal fistulas using thoracic endovascular aortic repair. J Vasc Surg 2009; 50: 999-1004.

22. Jonker FH, Schlosser FJ, Moll FL, et al. Outcomes of thoracic endovascular aortic repair for aortobronchial and aortoesophageal fistulas. J Endovasc Ther 2009; 16: 428-440. 
Copyright of Cardiology in the Young is the property of Cambridge University Press and its content may not be copied or emailed to multiple sites or posted to a listserv without the copyright holder's express written permission. However, users may print, download, or email articles for individual use. 